\title{
Crystal Structure and Packing Analysis of Nitrofurantoin N,N-dimethylformamide Solvate ${ }^{1}$
}

\author{
A. Cretkovski ${ }^{a}$ and V. Ferretti ${ }^{b}$ \\ ${ }^{a}$ University Goce Delcev, Faculty of Medical Sciences, Krste Misirkov bb, 2000 P.O 201, Štip, R. Macedonia \\ ${ }^{b}$ Department of Chemical and Pharmaceutical Sciences, University of Ferrara, \\ via Fossato di Mortara 17-27, I-44121 Ferrara, Italy \\ e-mail: aleksandar.cvetkovski@ugd.edu.mk \\ Received January 21, 2016
}

\begin{abstract}
The N, N'-dimethylformamide solvated crystal of the drug nitrofurantoin has been prepared and analysed by single-crystal $\mathrm{X}$-ray diffraction. The two co-crystallized molecules, in the $1: 1$ stoichiometric ratio, are linked by a medium/strong $\mathrm{N}-\mathrm{H} \cdots \mathrm{O}$ hydrogen bond $(\mathrm{N} \cdots \mathrm{O}$ is 2.759 (3) $\AA$ ) and a weaker $\mathrm{C}-\mathrm{H} \cdots \mathrm{O}$ interaction to form isolated supramolecular adducts, that in turn are packed into the lattice framework mainly through $\mathrm{C}-\mathrm{H} \cdots \mathrm{O}$ hydrogen bonds. Two-dimensional fingerprint plots of Hirshfeld surfaces are used to visualize, analyze and compare intermolecular interactions found in the title compound and in similar structures.
\end{abstract}

DOI: $10.1134 / \mathrm{S} 1063774516040040$

\section{INTRODUCTION}

Nitrofurantoin (chemical name: $(E)-1-[(5-$ nitro2-furyl) methylideneamino]-imidazolidine-2,4-dione) is an antibacterial drug used for the treatment of lower urinary tract infections; it works by killing the bacteria that cause the infection or by preventing the bacteria from growing. The drug acts in a complex way: inside the bacterial cells, it is activated by nitrofuran reductase and the resulting highly reactive nitrofurantoin reduced form is able to damage the DNA [1]. For the purpose of development pharmaceutical formulations, it presents the disadvantage of having low solubility, low permeability and hence low bioavailability. In the last years, the design and synthesis of co-crystals containing active pharmaceutical ingredients have represented a great opportunity to modify the physicochemical properties of solid forms of drugs. Actually, the pharmaceutical co-crystals display intermolecular motifs and hence crystal structure different from the pure drug component, and consequently can exhibit diverse specific physical properties, such as solubility and dissolution rate. As a part of our involvement in the investigation of co-crystals' structural features [2-4], we report here the synthesis, structure determination, and investigation of intercontacts by Hirshfeld surface analysis [5] of a new solvate co-crystal containing the active pharmaceutical ingredient nitrofurantoin.

\footnotetext{
${ }^{1}$ The article is published in the original.
}

\section{EXPERIMENTAL}

Synthesis. Crystals of the title compound have been prepared dissolving a small amount of nitrofurantoin in dimethylformamide solvent. After agitation, the solution have been slowly evaporated at room temperature. Pale yellow crystals were observed after a few days. All chemicals, purchased from Sigma-Aldrich, were of analytical or chromatographic grade and were used without further purification. For $\mathrm{C}_{11} \mathrm{H}_{13} \mathrm{~N}_{5} \mathrm{O}_{6}$ : Anal. calcd, (\%): C, 42.45; H, 4.21; N, 22.50. Found, (\%): C, 42.48; H, 4.25: N, 22.36.

$X$-ray structural analysis. X-ray structural analysis. A single crystal was carefully selected under polarizing microscope in order to perform its structural analysis by X-ray diffraction. Crystallographic data were collected on a Nonius Kappa CCD diffractometer at room temperature using graphite-monochromated MoK $\alpha$ radiation $(\lambda=0.71073 \AA)$. Data sets were integrated with the Denzo-SMN package [6] and corrected for Lorentz-polarization effects. The crystal parameters and other experimental details of the data collections are summarized in Table 1. The structures were solved by direct methods (SIR97) [7] and refined by full-matrix least-squares methods with all nonhydrogen atoms anisotropic. $\mathrm{H}$ atoms of the methyl groups were included on calculated positions, riding on their carrier atoms; all other hydrogen atoms were located in the Difference Fourier map and refined isotropically. All calculations were performed using SHELXL-97 [8] implemented in the WINGX system of programs [9]. Selected bond distances and angles 
Table 1. Crystallographic characteristics and X-ray-datacollection and structure refinement parameters of $\mathrm{C}_{11} \mathrm{H}_{13} \mathrm{~N}_{5} \mathrm{O}_{6}$

\begin{tabular}{|c|c|}
\hline System, sp. gr., $Z$ & Triclinic, $P \overline{1}, 2$ \\
\hline$a, b, c, \AA$ & $6.6391(3), 8.9453(4), 12.9761(7)$ \\
\hline$\alpha, \beta, \gamma, \operatorname{deg}$ & $97.160(2), 97.612(3), 106.187(2)$ \\
\hline$V, \AA^{3}$ & $722.92(6)$ \\
\hline$D_{x}, \mathrm{~g} \mathrm{~cm}^{-3}$ & 1.430 \\
\hline Radiation, $\lambda, \AA$ & $\operatorname{MoK}_{\alpha}, 0.71073$ \\
\hline$\mu, \mathrm{mm}^{-1}$ & 0.12 \\
\hline$T, \mathrm{~K}$ & 295 \\
\hline Sample size, $\mathrm{mm}$ & $0.29 \times 0.21 \times 0.18$ \\
\hline Diffractometer & Nonius Kappa CCD \\
\hline Scan mode & $\varphi$ and $\omega$ \\
\hline $\begin{array}{l}\text { Absorption correction, } \\
T_{\min }, T_{\max }\end{array}$ & None \\
\hline$\theta_{\max }, \operatorname{deg}$ & 28.0 \\
\hline$h, k, l$ ranges & $\begin{array}{l}-8 \leqslant h \leqslant 7 ;-11 \leqslant k \leqslant 11 \\
-17 \leqslant l \leqslant 16\end{array}$ \\
\hline $\begin{array}{l}\text { Number of reflections: } \\
\text { measured/unique }(N 1) \text {, } \\
R_{\text {int }} / \text { with } I>3(I)(N 2)\end{array}$ & $5644 / 3465,0.025 / 2224$ \\
\hline Refinement method & Full-matrix least-squares on $F^{2}$ \\
\hline $\begin{array}{l}\text { Number of refined } \\
\text { parameters }\end{array}$ & 228 \\
\hline$R 1 / w R 2$ relative to $N 1$ & $0.097 / 0.202$ \\
\hline$R 1 / w R 2$ relative to $N 2$ & $0.063 / 0.173$ \\
\hline$S$ & 1.00 \\
\hline$\Delta \rho_{\max } / \Delta \rho_{\min }, \mathrm{e} / \AA^{3}$ & $0.39,-0.23$ \\
\hline Program package & $\begin{array}{l}\text { Denso-SMN [6], SIR97 [7], } \\
\text { SHELXL [8], WingX [9], } \\
\text { ORTEPIII [10], Diamond [11] }\end{array}$ \\
\hline
\end{tabular}

Table 2. Selected bond lengths $d(\AA)$ and bond angles $\omega$ (deg)

\begin{tabular}{l|l||l|l}
\hline $\mathrm{C} 1-\mathrm{O} 1$ & $1.199(3)$ & $\mathrm{C} 1-\mathrm{N} 2$ & $1.378(3)$ \\
$\mathrm{C} 1-\mathrm{N} 1$ & $1.382(3)$ & $\mathrm{C} 2-\mathrm{O} 2$ & $1.205(3)$ \\
$\mathrm{C} 2-\mathrm{N} 1$ & $1.355(3)$ & $\mathrm{C} 3-\mathrm{N} 2$ & $1.454(2)$ \\
$\mathrm{N} 2-\mathrm{N} 3$ & $1.363(2)$ & $\mathrm{C} 4-\mathrm{N} 3$ & $1.288(3)$ \\
$\mathrm{O} 4-\mathrm{N} 4$ & $1.208(3)$ & $\mathrm{O} 5-\mathrm{N} 4$ & $1.236(3)$ \\
$\mathrm{C} 9-\mathrm{O} 6$ & $1.225(4)$ & & \\
$\mathrm{O} 1-\mathrm{C} 1-\mathrm{N} 1$ & $127.0(2)$ & $\mathrm{O} 1-\mathrm{C} 1-\mathrm{N} 2$ & $127.3(2)$ \\
$\mathrm{O} 2-\mathrm{C} 2-\mathrm{N} 1$ & $125.8(2)$ & $\mathrm{O} 2-\mathrm{C} 2-\mathrm{C} 3$ & $127.2(2)$ \\
$\mathrm{N} 3-\mathrm{N} 2-\mathrm{C} 1$ & $119.8(2)$ & $\mathrm{N} 3-\mathrm{N} 2-\mathrm{C} 3$ & $127.6(2)$ \\
$\mathrm{C} 4-\mathrm{N} 3-\mathrm{N} 2$ & $115.8(2)$ & $\mathrm{O} 4-\mathrm{N} 4-\mathrm{O} 5$ & $124.9(2)$ \\
$\mathrm{O} 6-\mathrm{C} 9-\mathrm{N} 5$ & $126.2(3)$ & & \\
\hline
\end{tabular}

are given in Table 2. The drawings were made with ORTEPIII [10] and Diamond [11].

Crystallographic data have been deposited with the Cambridge Crystallographic Data Centre, CCDC number 1447209. Copies of the data can be obtained free of charge on application to CCDC, 12 union Road, Cambridge CB2 1EZ, UK (fax: (+44) 1223- 336033; e-mail: deposit@ccdc.cam.ac.uk).

Hirshfeld surfaces and fingerprints evaluation. Molecular Hirshfeld surfaces [5] and their 2D-fingerprint $[12,13]$ have been evaluated for the present compounds and other related molecules whose structures have been retrieved from the Cambridge Crystallographic Database [14] to get additional insight into the intermolecular interactions of molecular crystals. Actually, the Hirshfeld surface represents the molecule when interacting with the crystal environment and the decomposition of this surface gives a 'molecular fingerprint', a 2D map indicating not only which intermolecular interactions are present, but also the relative area of the surface corresponding to each kind of interaction. The Hirshfeld surfaces and 2D fingerprint plots were generated using CrystalExplorer 3.0 [15].

\section{RESULTS AND DISCUSSION}

An ORTEPIII view of the asymmetric unit is shown in Fig. 1. Selected bond distances and angles are given in Table 2 . The crystal is formed by nitrofurantoin and dimethylformamide molecules in $1: 1$ stoichiometric ratio. The drug molecule, excluding the $\mathrm{H}$ atoms, is not far from planar, the maximum displacement from the mean molecular plane being $0.181(2)$ and $0.298(2) \AA$ for the O4 and O2 atoms, respectively. The $E$ molecular configuration with respect to the $\mathrm{C} 4=\mathrm{N} 3$ double bond found in the pure drug crystal is conserved: the N2-N3-C4-C5 torsion angle is equal to $-179.2(2)^{\circ}$. Bond distances and angles are regular and are in agreement with those

Table 3. Hydrogen-bond geometry. The $\mathrm{C}-\mathrm{H} \cdots \mathrm{O} / X$ interactions where the $\mathrm{H} \cdots X$ distance is less than sum of van der Waals radii and $\mathrm{C}-\mathrm{H} \cdots X$ angle is greater than $130^{\circ}$ are considered to be significant

\begin{tabular}{l|l|l|l|l}
\hline \multicolumn{1}{c|}{$D-\mathrm{H} \cdots A$} & $D-\mathrm{H}, \AA$ & $\mathrm{H} \cdots A, \AA$ & $D \cdots A, \AA$ & $\begin{array}{c}D-\mathrm{H} \cdots A, \\
\mathrm{deg}\end{array}$ \\
\hline $\mathrm{N} 1-\mathrm{H} \cdots \mathrm{O} 6$ & $0.83(3)$ & $1.95(3)$ & $2.759(3)$ & $164(3)$ \\
$\mathrm{C} 9-\mathrm{H} \cdots \mathrm{O} 2$ & $1.07(4)$ & $2.38(4)$ & $3.251(4)$ & $138(3)$ \\
$\mathrm{C} 11-\mathrm{H} \cdots \mathrm{O} 2^{\mathrm{i}}$ & 0.96 & 2.35 & $3.306(4)$ & 168 \\
$\mathrm{C} 11-\mathrm{H} \cdots \mathrm{O} 5^{\mathrm{ii}}$ & 0.96 & 2.57 & $3.339(4)$ & 137 \\
$\mathrm{C} 3-\mathrm{H} \cdots \mathrm{O} 2^{\mathrm{iii}}$ & $0.94(3)$ & $2.41(3)$ & $3.324(3)$ & $165(2)$ \\
$\mathrm{C} 4-\mathrm{H} \cdots \mathrm{O} 1^{\mathrm{iv}}$ & $0.94(2)$ & $2.27(2)$ & $3.116(3)$ & $149(2)$ \\
\hline
\end{tabular}

Symmetry codes: (i) $x-1, y, z$; (ii) $x-1, y+1, z-1$; (iii) $-x+1$, $-y+1,-z+1$; (iv) $x+1, y, z$ 


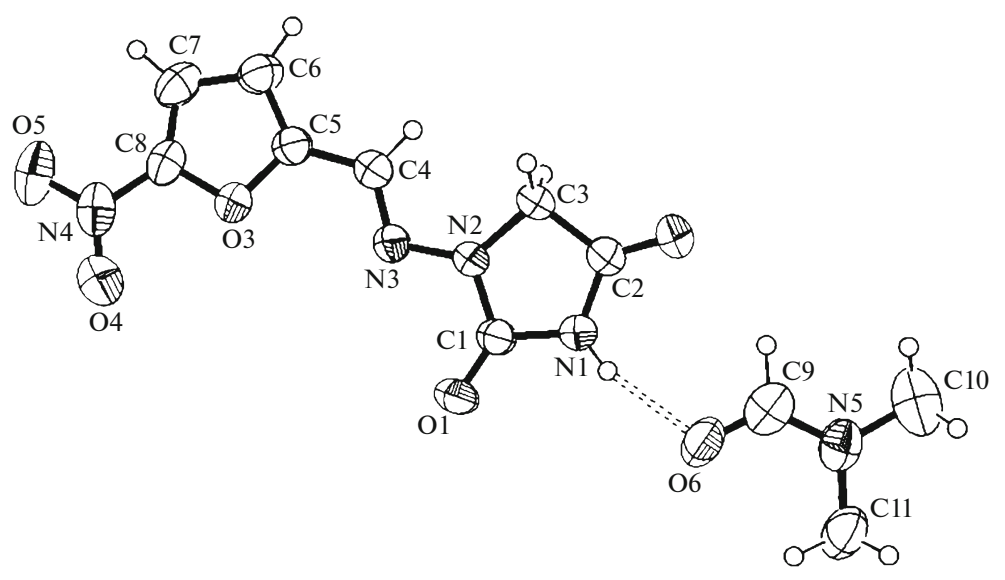

Fig. 1. ORTEP(III) view and atom numbering scheme for the title compound. Thermal ellipsoids are drawn at the $50 \%$ probability level. Hydrogen bond is drawn as dashed line.

found in nitrofurantoin co-crystals retrieved from the Cambridge Crystallographic Database [20 hits, refs. 16-20].

The nitrofurantoin and dimethylformamide molecules are connected by the $\mathrm{N} 1-\mathrm{H} \cdots \mathrm{O} 6$ hydrogen bond shown in Fig. 1 to give an isolated supramolecular adduct; the coupling of the two moieties is made more robust by a $\mathrm{C} 9-\mathrm{H} \cdots \mathrm{O} 2$ short contact. Owing to the scarcity of hydrogen bond donors with respect to acceptors, the packing is completed by a number of $\mathrm{C}-\mathrm{H} \cdots \mathrm{O}$ interactions, listed in Table 3 , which can be considered weak hydrogen bonds. In Fig. 2, all the interactions around a nitrofurantoin molecule are shown. The closest contacts involve the imidazolidine fragment of the drug molecule; the terminal nitro group, which is known to be a poor hydrogen bonder, is implicated only in the weakest interaction (C11$\mathrm{H} \cdots \mathrm{O} 5$ in Table 3 ).

It is worth to compare this packing mode with that found in similar structures, where nitrofurantoine molecule is co-crystallized with dimethylsulfoxide (CSD code: AKEMAF) or dimethylacetamide (CSD code: AKEMIN) [16], i.e. molecules that are very similar to dimethylformamide as far as the size and the functional groups are concerned. The comparison revealed that the just described interaction pattern is almost perfectly conserved and the packing is determined for the most part by very weak interactions. To better visualize and analyze the intermolecular interactions of the nitrofurantoin moiety in these crystals, the Hirshfeld surface's 2D fingergerprint plot [5, 12, 13] of the drug molecule in each of them have been generated. The function mapped onto the Hirshfeld surface is $d_{\text {norm }}$, i.e. the so-called normalized contact distance; it is defined in terms of $d_{e}$ (distance to the nearest atoms outside), $d_{i}$ (distance to the nearest atoms inside) and the van der Waals radii of the two atoms external and internal to the surface. In Fig. 3, the Hirshfeld surface for nitrofurantoin in the title crystal is shown. When the values of $d_{i}$ and $d_{e}$ for any surface point are plotted against each other, the fin-

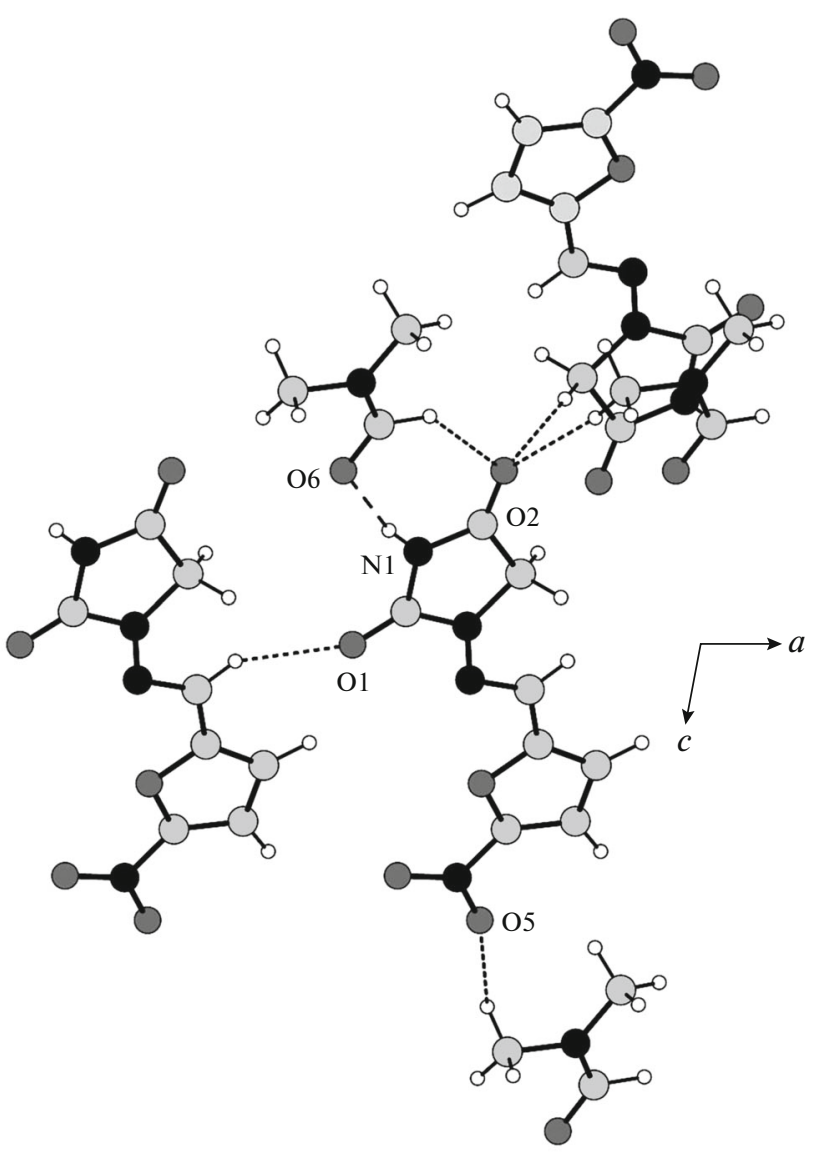

Fig. 2. $\mathrm{N}-\mathrm{H} \cdots \mathrm{O}$ (dashed lines) and $\mathrm{C}-\mathrm{H} \cdots \mathrm{O}$ (dotted lines) interactions in the title compound. 


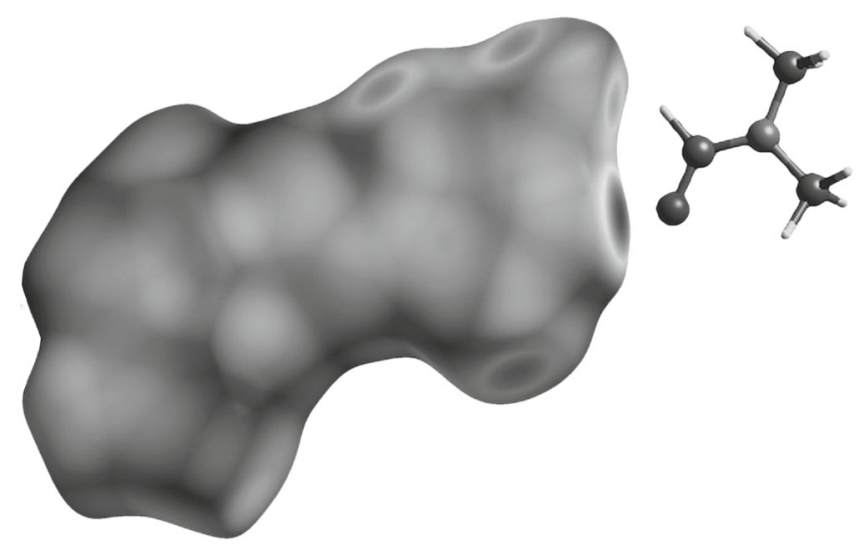

Fig. 3. Nitrofurantoin Hirshfeld surface in dimethylformamide co-crystal (color code: black spots = distances shorter than the sum of vdW radii; white $=$ distances equal to the sum of vdW radii; grey $=$ contacts longer than the sum of vdW radii).
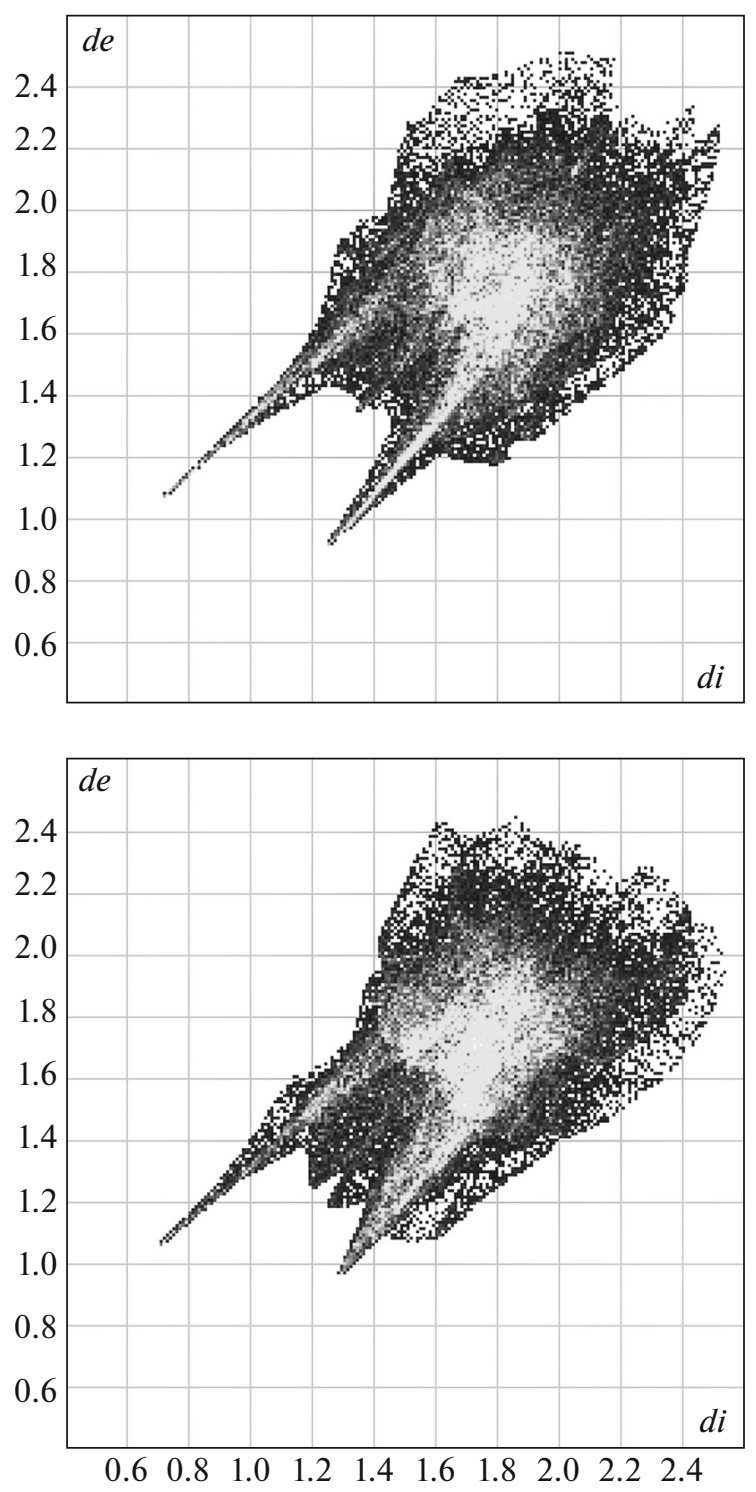

gerprint plots are obtained. Here the different colours are related to the density of points giving that particular $d_{i}-d_{e}$ combination: for high density the colour is black, for moderate density the colour is white, and for relatively few points the colour is grey. It is also possible to highlight on the plot a single contact of the type atomtype $1 \cdots$ atomtype 2 , to focus the attention on the individual interaction types present [21]. The plots for the title compound, AKEMIN and AKEMAF are shown in Fig. 4. They all are very similar. Globally, $\mathrm{H}$... O interactions are the most abundant in the crystal packing, since the percentage surface coverage for this individual interaction type is $54.0,46.8$ and $47.6 \%$ for the title compound, AKEMIN and AKEMAF, respectively. This is in line with the values reported in Table 3, which actually indicate that $\mathrm{H} \cdots \mathrm{O}$ contacts are the most important in the packing pattern of the present structure; accordingly, this type of interaction

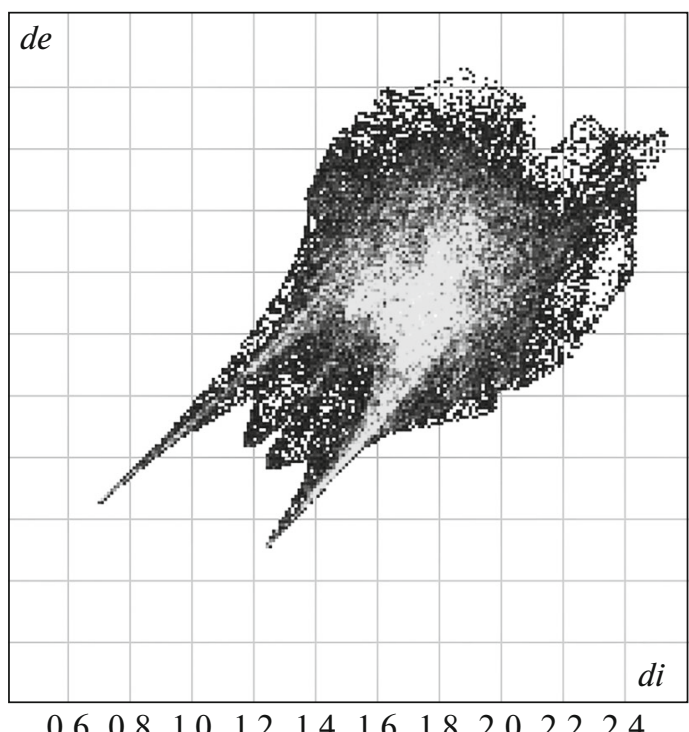

(b)

(c)

Fig. 4. Fingerprint plots for the title compound (a), AKEMAF (b) and AKEMIN (c), respectively. 
appears to have enriched occurrences in all the three considered co-crystals. The two sharp peaks in each plot correspond to the most important $\mathrm{N}-\mathrm{H} \cdots \mathrm{O}$ and $\mathrm{C}-\mathrm{H} \cdots \mathrm{O}$ hydrogen bonding interactions. $\mathrm{C}-\mathrm{H} \cdots \mathrm{H}-\mathrm{C}$ contacts produce a sharper spike in the centre of the fingerprint plot; since the shape of the fingerprint is related to the angle of contact [22], this means that there are AKEMIN and AKEMAF $\mathrm{H} \cdots \mathrm{H}$ contacts which are more direct head-to-head than in dimethylformamide co-crystal.

\section{CONCLUSIONS}

A new solvated crystal containing the active pharmaceutical ingredient nitrofurantoin has been synthesized and structurally characterized with X-ray diffraction. The two co-crystallized molecules are linked via $\mathrm{N}-\mathrm{H} \cdots \mathrm{O}$ hydrogen bonds forming bimolecular adducts, which in turn interact with each others through $\mathrm{C}-\mathrm{H} \cdots \mathrm{O}$ weaker interactions. Hirshfeld analysis applied to the present structure and to other similar solvated nitrofurantoin co-crystal retrieved from CSD have shown that this packing mode is highly reproducible.

\section{REFERENCES}

1. Y. Tu, and D. R. McCalla, Biochem. Biophys. Acta 402, 142 (1975).

2. V. Bertolasi, P. Gilli, V. Ferretti, and G. Gilli, Acta Crystallogr. B 57, 591 (2001).

3. V. Bertolasi, L. Pretto, P. Gilli, V. Ferretti, and G. Gilli, New J. Chem. 26, 1559 (2002).

4. V. Ferretti, A. Dalpiaz, V. Bertolasi, L. Ferraro, S. Beggiato, F. Spizzo, E. Spisni, and B. Pavan, Mol. Pharmaceutics 12, 1501 (2015).
5. F. L. Hirshfeld, Theor. Chim. Acta, 44, 129 (1977).

6. Z. Otwinowski and W. Minor, Methods Enzymol. 276, 307 (1997).

7. A. Altomare, M. C. Burla, M. Cavalli, G. Cascarano, C. Giacovazzo, A. Gagliardi, A. G. Moliterni, G. Polidori, and R. Spagna, J. Appl. Crystallogr. 32, 115 (1999).

8. G. M. Sheldrick, Acta Crystallogr. A 64, 112 (2008).

9. L. J. Farrugia, J. Appl. Crystallogr. 32, 837 (1999).

10. M. N. Burnett, and C. K. Johnson, ORTEPIII. Report ORNL-6895 (Oak Ridge National Laboratory, Oak Ridge, Tennessee, USA, 1996).

11. K. Brandenburg, DIAMOND Version 2.0 (1998).

12. M. A. Spackman, and J. J. McKinnon, CrystEngComm 4, 378 (2002).

13. J. J. McKinnon, D. Jayatilaka, and M. A. Spackman, Chem. Commun. 3814 (2007).

14. F. H. Allen, Acta Crystallogr. B 58, 380 (2002).

15. S. K. Wolff, D. J. Grimwood, J. J. McKinnon, M. J. Turner, D. Jayatilaka, and M. A. Spackman, CrystalExplorer (Version 3. 0) (Univ. of Western Australia, 2012).

16. M. Tutughamiarso, M. Bolte, G. Wagner, and E. Egert, Acta Crystallogr. C 67, o18 (2011).

17. A. Alhalaweh, S. George, S. Basavoju, S. Childs, S. A. A. Rizvi, and S. Velaga, CrystEngComm 14, 5078 (2012).

18. V. R. Vangala, Pui Shan Chow, R. B. H. Tan, CrystEngComm 13, 759 (2011).

19. V. R. Vangala, Pui Shan Chow, R. B. H. Tan, CrystEngComm 15, 878 (2013).

20. S. Cherukuvada, N. J. Babu, A. Nangia, J. Pharm. Sci. 100, 3233 (2011).

21. M. Spackman, and D. Jayatilaka, CrystEngComm, 11, 19 (2009).

22. J. J. McKinnon, M. A. Spackman and A. S. Mitchell, Acta Crystallogr. B 60, 627 (2004). 